\title{
Vana traditsioon, noored esitajad
}

\begin{abstract}
Aado Lintrop
Teesid: Suurem osa Wolfgang Steinitzi handialaste tööde esimeses ja kolmandas köites avaldatud jutu- ja laulutekste on silmapaistva mütoloogilise taustaga ning on ühel või teisel viisil kogutud Leningradi Põhjarahvaste Instituudi üliõpilastelt. Noored mehed tundusid olevat head traditsioonilise laulu- ja juturepertuaari tundjad. Aga kui head? Milline on nende laulude ja juttude asend obiugrilaste folkloorimaastikul? Neile küsimustele otsingi vastuseid.

Kõigepealt vaatlen karupeo laule üldisel usundilis-folkloorsel taustal, näidates ära peamised iseloomulikud ühtelangevused poeetilisel ja mütoloogilisel tasandil. Seejärel näitan, milliseid traditsioonilisi elemente sisaldab Dimitri Tebitevi loodud laul Leninist. Viimaks iseloomustan lühidalt ka narratiive, millest osa kuulub mütoloogiliste muistendite hulka.
\end{abstract}

Märksõnad: handi folkloor, handi muistendid, handi mütoloogia, handi mütoloogilised laulud, karupeied, karupeolaulud, karupidu, obiugri folkloor, obiugri mütoloogia

Artiklis analüüsin Wolfgang Steinitzi handialaste tööde (Ostjakologische Arbeiten) esimeses ja kolmandas köites avaldatud jutu- ja laulutekste. 106 teksti esindavad üheksat handi murdeala, 68 neist on narratiivid ning nende päritolu on järgmine: 49 teksti saadi Kirill Maremjaninilt, 18 teksti Prokop Põrõsevilt, kuus teksti P. Tšamzarovilt, viis teksti A. Olginalt, kolm Dimitri Tebitevilt ja sama palju G. Artanzejevilt. 20 teksti kogus W. Steinitz ise 1935. aasta ekspeditsiooni ajal erinevatelt inimestelt ning ühe laulu sai ta 1963. aastal Leningradis käies. 29 teksti on kirja pandud informantide endi poolt ning W. Steinitzi kontrollitud või parandatud, ülejäänud tekstid litereeris W. Steinitz ise. 1936. aastal salvestati fonograafile üks jutt ja 18 laulu, kõigi esitajaks K. Maremjanin.

Suurem osa tekste on silmapaistva mütoloogilise taustaga. Minule osutus kõige intrigeerivamaks fakt, et 85 teksti koguti ühel või teisel viisil Leningradi Põhjarahvaste Instituudi üliõpilastelt - oleme ju harjunud sellega, et autentsemat vana pärimust teavad peamiselt eakad inimesed. Ajal, mil 
W. Steinitz nimetatud tekstid kogus (peamiselt 1936. aastal), oli vanim ta üliõpilastest, Dimitri Tebitev, umbes 30, Kirill Maremjanin 29 ja Prokop Põrõsev 18 aastat vana. Sellest hoolimata tundusid nad olevat head traditsioonilise laulu- ja juturepertuaari tundjad. Aga kui head? Milline on nende laulude ja juttude asend obiugrilaste folkloorimaastikul? Neile küsimustele otsingi vastuseid.

38 avaldatud laulust kuulub 28 teksti karupeo repertuaari hulka. Nende

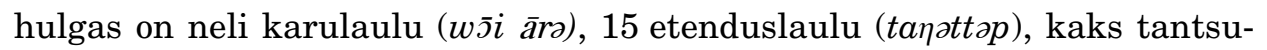
laulu ja seitse vaimude ilmumislaulu (W. Steinitzil Geistertanzlieder - üna jāk ārə-Lied des erhabenen Tanzes). Ülejäänud kümnest tekstist võib seitse liigitada isikulaulude hulka, üks on mütoloogiline laul (torstor- ̌̌ ki), üks vaba tõlge vene keelest (Tšapajev) ja üks D. Tebitevi omalooming (Lenin). Oma 1997. aastal avaldatud artiklis analüüsisin esimeses köites avaldatud 22 lauluteksti, mis kõik olid seotud karupeo repertuaariga (Lintrop 1997: 70-98). Kõik need tekstid olid saadud Kirill Maremjaninilt. Tuleb rõhutada, et 17 teksti on kirja pandud laulmise järgi ning sisaldavad seega ka sõnade meloodiaga sobitamiseks vajalikke täitesilpe.

Järgnevalt tutvustan lühidalt obiugrilaste karupidu, mis on omapärane institutsioon pärimuse säilitamiseks ja edasiandmiseks. Selle keskmeks on karu kui mütoloogilise tegelase külaskäik inimeste juurde. Karu erilisusest

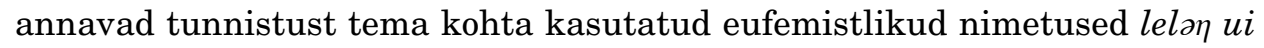
'hingega loom' ning jalpə⿱ ui 'püha loom'. Paljudes karulauludes esineb karu taevajumala hellitatud ja sõnakuulmatu lapse rollis, kes saavutab oma tahtmise pääseda alla inimeste maale, kuid jääb ilma kõikvõimsa isa soosingust. Taevajumal ei hakka kehtivat maailmakorda ühe jonnaka lapse pärast muutma. Sääsed ja parmud, külm talvine tuul ja läbipääsmatud tihnikud ning tümad sood viivad looma nii kaugele, et ta unustab kõik keelud. Ja kuna ta osutub väljaspool seadust olevaks, on inimesel õigus teda tappa. Sellistes lauludes meenutab karu langenud inglit. Tuletame meelde, et ka allilma valitseja esineb mansi folklooris taevajumala jonnaka pojana, kelle isa lõpuks taevast alla heidab. Samas on karu olend, keda inimesed vastu võtavad ja kostitavad kui kallist külalist, sest ta pole mitte alatiseks oma taevase isa juurest pagendatud, vaid läheb sinna tagasi. Karu tapmine on tema jumaliku seisundi taastamine. Olles maa peale lastud, pääseb ta isa juurde tagasi vaid maise keha surmamise kaudu. Obiugrilaste karuga seotud lugu on metsarahvale kohandatud variant põlluharijatele iseloomulikust sureva ja taassündiva jumaluse müüdist.

Karupidu võiks nimetada religioosseks laulumänguks, mille stsenaarium on lühidalt järgmine: inimesed tervitavad kallist külalist (karu), panevad ta aukohale istuma, kostitavad teda ning lõbustavad laulude-tantsudega. Lau- 
lude sisuks on karu elulugu ja pidumajja jõudmise kirjeldused. Pidukära kuulevad ka mitmesugused mütoloogilised tegelased, kes lauljate poolt kehastatutena rahva ette astuvad ning ennast tutvustavad. Esmakordsel tekstidega tutvumisel rababki selliste laulude konkreetsus. Tüüpiline on skeem: mina haldjas (haldjatar) elan seal ja seal, kuulsin, et peetakse pidu laiapihalise soo-metslooma auks, panin selga need ja need rõivad ja asusin ühel või teisel kombel (jalgsi, paadiga, põdrarakendiga) teele, tulin sealt ja sealtkau$\mathrm{du}$, jõudsin inimestest tulvil pidumajani. Karupidu võib mõneti võrrelda preventiivse šamaanirituaaliga, sest laulude lõpuosas pakuvad jumalused kogukonnale kaitset ja eestkostet nende "haldusalustes" küsimustes, näiteks:

Viiekeelse keelepuu

alumist keelt kui helistatakse,

alumiste vaimude viisihääl

seal võib kõlada;

ülemist keelt kui helistatakse,

ülemiste vaimude viisihääl

seal võis kõlada.

Minu paljud majas istuvad naised, mis ma teile nüüd jätan?

Veekalaõnne tantsu, oma tantsu ma jätan teile, metsloomaõnne tantsu, oma tantsu ma jätan teile

(Steinitz 1939: 345-346, värsid 124-136).

Tegelikult on kogu karupidu omamoodi müsteerium, milles karu sümboliseerib inimeste juurde laskunud jumalust, kes tuleb kontrollima, kas loomisaegadel kehtestatud mängureeglid on inimestele veel siduvad, ehk teisisõnu - kuivõrd hästi on inimesed teadlikud oma kohast maailmas. Karupeost kui institutsioonist rääkides on aga pidumajja saabuv laiapihaline soo-metsloom otsekui visitatsiooni sooritav kõrge kirikutegelane, kelle ees nii inimesed kui ka üleloomulikud olendid peavad üles astuma. Seepärast saabuvadki pidumajja paljud haldjad ja jumalused, kes lauljate suu läbi räägivad oma päritolust, elupaigast ja tegemistest. Sellepärast peetakse laulude üle ranget arvestust, ja kui mõni kohustuslik laul ununeb, tuleb pidu kas ära jätta või kutsuda külla keegi, kes vajalikku laulu mäletab. Ning sellepärast on karupeiete laulud nii konkreetsed, sisaldades palju usundi- ja kombestikualast teavet. Näiteks võib tuua veel katkendi Sosva-äärsetelt mansidelt kogutud karupeo lõpulaulust, sealse rahva pühast laulust (selle lõpuosa ei tohtinud naised ja lapsed kuulda): 
Kaua käisin või vähe käisin,

Numi-Toorumi, oma isakese,

Numi-Toorumi, oma taadikese

kuldse maja ukse ju avasin,

kuldsesse majja sisse astusin.

Paunselgse mäehiiuna sisse astusin, paunselgse metshiiuna sisse astusin, oma isakese sooblinahksele põlvele, karusnahksele põlvele istusin.

Isake ütleb:

"Inimese majja laskunud tütreke, oledki tagasi."

"Olengi tagasi."

Seljakõrgusest pikast kotist ammutasin

isakese paljudele noolepoegadele, paljudele vibupoegadele

piisavalt kalevit igaühele jagasin,

piisavalt siidi igaühele jagasin.

Mu isa ütles:

"Inimese elumaja nurka

sa laskusid.

Kuidas sind koheldi?"

(Steinitz 1939: 382-383, värsid 255-275).

Seepeale loeb karu üles kõik need seigad, mis teda pahandasid nii inimeste juures kui ka koduteel. Ta palub isal süüdlasi karistada. Ent Numi-Toorum vabandab süüdlased välja rumalusega. Ta ütleb, et kõik nad on tema poolt sellisteks loodud ning seepärast pole neid vaja nuhelda. Laul jätab otsustamisõiguse taevajumalale ja annab selgesti mõista, et tõsiste eksimuste korral ja süüd pehmendavate asjaolude puudumisel võib järgneda karistus.

Nüüd vaatame, kuidas on lauludes kirjeldatud mütoloogiliste tegelaste elukohti, s.o neile pühendatud tähtsamaid pühapaiku. Vaimude ilmumislauludest, mida lauldakse peopäeva viimases osas, on esimesena 29. numbri all "Kevadoravanahkse Andamiga Valitseja laul”, millega tutvustatakse Maailmavaatavat Meest. Tema elupaika kirjeldatakse järgmiste sõnadega:

Hommiku ajal kasvanud

kuldse muruga kasvatatud neemel,

ôtu ajal kasvanud

kuldse rohuga kasvatatud neemel;

kevadmetsisekuke sulgedega kaetud küngastel, sügismetsisekuke sulgedega kaetud küngastel; 
jooksva pilve kõrgusel, sammuva pilve kõrgusel minu kuukirja püha maja, minu päikesekirja püha maja kuldse keti kallis otsas seal see ripub, kuldse hõbeda kallis otsas seal see ripub.

Lõunakõrist kõriline tuul kui tõuseb, väikese hõbeda kõlina kõlal põhjapoolse Obi kalli vee poole seal see liigub.

Põhjakõrist kõriline tuul

kui tõuseb, suure hõbeda kõlina kõlal lõunapoolse Obi kalli vee poole seal see liigub

(Steinitz 1939: 339-341, värsid 1-24).

Lõuna ja põhi on tekstis seotud Obi jõega, lõunat tähistab sõna numən ülemine, põhja owsen - suudmepoolne. Nagu edaspidi näeme, mainitakse ka mitmes teises kutsumislaulus hõbeketti, kuid ikka seoses hälliga, milles üks või teine jumalus väidab end taevast alla lastud olevat. Maja ripub keti otsas vaid Maailmavaatava Mehe ja Kaltaši noorema poja lauludes. Epiteedid kuukirja ja päikesekirja aga seostuvad W. Steinitzi tekstides mitmetele eri jumalustele kuuluvate asjadega. Samas esineb päikesekirja maja taevajumala ja tema laste eluasemena ka mansi laulus (Great Bear: 109). Arusaamatu on, miks tõlgib W. Steinitz värsis 13 wo ðə vaseks, kui kõikjal mujal tähendab see hõbedat. Värssides 17 ja 22 on ta sama sõna koguni hõbetükkideks tõlkinud. Paralleelvärssides 7 ja 8 vahelduvad sõnad jooksev ja sammuv tähendavad kokku liikumist. Sama sõnapaari kasutatakse Püha Linna Taadi eluaseme kirjeldamiseks - jooksva hobuse kujuline linn, sammuva hobuse kujuline linn.

Võrdleme nüüd lauludes kirjeldatud suundi, kust väidetavasti kuuldi laiapihalise soo-metslooma auks peetud peo kära.
A) Maailmavaatav Mees
Valvsa auli terava kõrvaga
ma nü̈̈ kuulen:
põhjapoolse Obi kalli vee juures, põhjapoolse Obi hüva vee juures; 
kolme haruneva vee juures, nelja haruneva vee juures; hanesulemehe sukeldumise vee juures, pardisulemehe sukeldumise vee juures laiapihalise soo-metslooma lustimaja kuuldavasti peetakse (Steinitz 1939: 342-343, värsid 60-69).

\section{B) Kaltaš}

Valvsa auli terava kõrvaga lõunapoolse Obi kallist vett, mina, haldjatar, kuulan.

Valvsa auli kahe terava kõrvaga, mina, haldjatar, kuulen...

(Steinitz 1939: 349, värsid 41-45).

\section{C) Kazõmi jõe haldjatar}

Valvsa auli terava hea kõrvaga mina, haldjatar, kuulen:

lõunapoolse Obi kalli vee juures laiapihalise soo-metslooma lustimaja kuuldavasti peetakse (Steinitz 1939: 364, värsid 25-29).

D) Allilma Isand (Väikeseid tüdrukuid neelav isand)

Lõunapoolse Obi kalli vee ä̈̈res, seitsme Obi-linna taga, kuue Obi-linna taga, ma kuulsin

ilmakeskme kuulsa vee ääres, maakeskme kuulsa vee ääres laiapihalise soo-metslooma lustimaja kuuldavasti peetakse (Steinitz 1939: 378-379, värsid 17-24).

\section{E) Püha Linna Taat}

Valvsa auli terava kõrvaga ma kuulsin:

lõunapoolse Obi kalli vee ääres, kolme haruneva vee ääres laiapihalise soo-metslooma lustimaja kuuldavasti peetakse (Steinitz 1939: 386, värsid 28-33). 


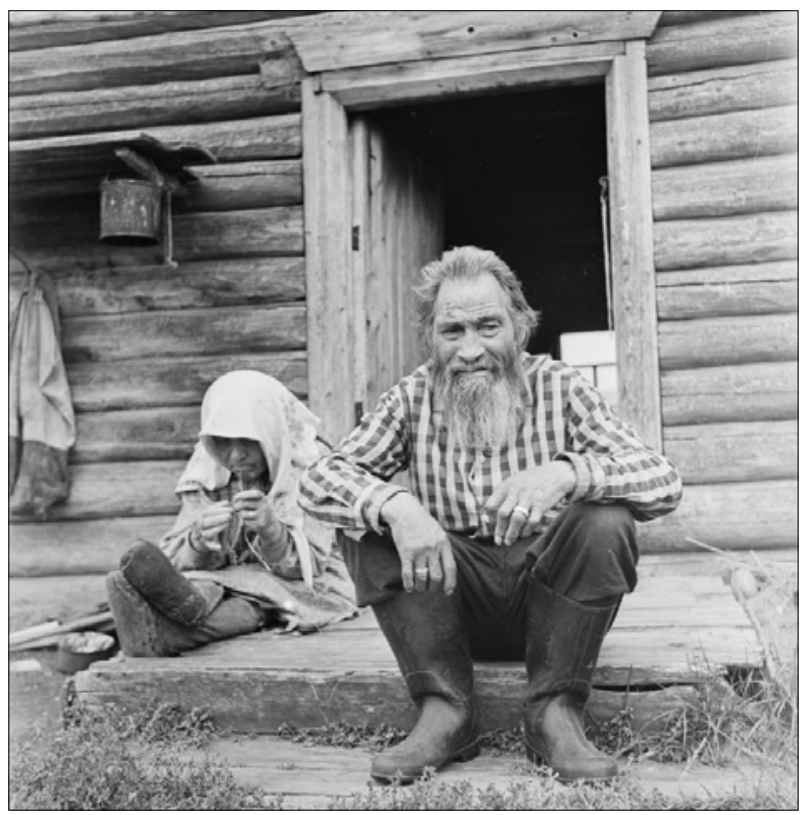

Foto 1. Folkloristid eeldavad, et reeglina on head pärimuse tundjad vanemad inimesed. Pildil mansi jutustaja ja laulik Roman Sainahhov (Roman-oika) koos naisega. Handi-Mansi AR, Berjozovo raj. Sukerja küla. Foto A. Lintrop 1977. ERM FK 1916:52.

Laulutekstidest selgub, et pidumaja paikneb Maailmavaatava Mehe elupaigast põhja pool, kuid lõuna pool Kazõmi haldjatari, Kaltaši, Püha Linna Taadi ja Allilma Isanda elamutest. Kui meil on tegemist konkreetse karupeo repertuaariga, pidi see aset leidma kusagil Belogorje ja Kazõmi vahel. Vaadates W. Steinitzi koguteose teises köites publitseeritud kaarti, näeme, et laulude esitaja Kirill Maremjanini koduküla Lohtotgurt paikneb just selles piirkonnas.

Järgmiseks vaatame, kuidas kirjeldatakse lauludes mütoloogilisi tegelasi. Éva Schmidti järgi kasutasid obiugrilased eepilistes lauludes kangelaste tabuliste nimede asemel mitmesuguseid eufemisme (nagu kaks (kolm) vibu ja nooltega meest, kaks (kolm) metshane lasknud meest), mida sageli pole võimalik identifitseerida (Schmidt 1989: 201). Karupeietelgi kandsid hald-

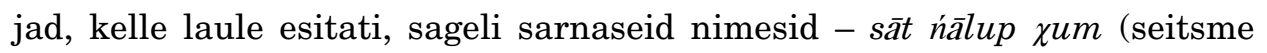
noolega mees), kit vil'tup japal (kahe näoga haldjas - Tšernetsov 1974: 292, 302), $t \bar{\jmath} w$ tā̄k $\bar{u} t a \eta \chi \bar{\jmath} n$ (kevadoravanahkse andamiga valitseja - Steinitz

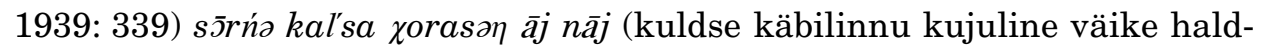

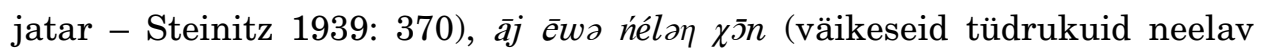
valitseja - Steinitz 1939: 377). 
On oluline rõhutada, et igal vaimul on minimaalne hulk tunnuseid, mis on vajalikud selleks, et vaatajad-kuulajad saaksid ta ära tunda. Kogumiku Ostjakologische Arbeiten teises köites leiame hea vaimude kutsumislaulude esitamise kirjelduse:

Vaimude tantsulaule esitatakse ühel karupeo viimastest öödest. Laulja siseneb piduruumi, tervitab karu ja hakkab laulma. Harilikult kannab laulja ohvrimantlit. Kui tegemist on naissoost vaimuga, katab laulja oma pead ja nägu rätiga. Kaltaš-eide laulu esitades paneb laulja selga tavalise naistekleidi. Ta ei kanna maski. Laul algab vaimu elupaiga - s.t tema pühapaiga - kirjeldamisega. Vaim kuuleb kaugest külast kostvat karupeolaulude kaja, tõuseb, rõivastub ja läheb pidumajja. Kui laulik jõuab lauluga nii kaugele (harilikult 100-120 värsini), avaneb pidumaja uks ja vaim ilmub. Ta on rõivastatud just nii, nagu vastavat vaimu ette kujutatakse: ta kannab ohvrimantlit, mis mõne vaimu puhul peab olema kindlat värvi, kui ta on meessoost vaim, siis on tal peas müts, kui naissoost, siis rätt. Ta seljal ja ôlgadel ripub arvukalt ohverdatud karusnahku, urt1 ilmub ratsa "kimli" seljas jne. Kui tulija on tähtis vaim, tõusevad kõik juuresviibijad püsti, paljastavad pea ja kummardavad. Vaim läheb karu poole, kummardab talle ning peoperemees suitsetab teda hõõguva taelaga. Seejärel alustab vaim muusika saatel tantsu. Igal vaimul on oma tants omade eriliste liigutustega. Tantsiv vaim ei lausu sõnagi. Pärast tantsu lõpetamist ta kummardab karu ees ja lahkub (Steinitz 1976: 275).

Võrdleme nüüd lauludes esinevaid vaimude kirjeldusi.

\section{A) Kaltaš}

Tüdrukuid Läkitav Väike Vihane Haldjatar,

Poisse Läkitav Väike Vihane Haldjatar -

mu nime teatakse.

Väikestele tüdrukutele pikka iga

mina, haldjas, mä̈̈ran;

väikestele poistele pikka head iga

mina, haldjas, määran

(Steinitz 1939: 348, värsid 26-32).

Obiugrilaste mütoloogias on Kaltaš see jumalus, kes peab arvet inimeste elupäevade üle ning saadab inimeste juurde sündivate laste hinged. Teda iseloomustatakse sageli kui tüdrukuid läkitavat ja väikes vihast haldjatari

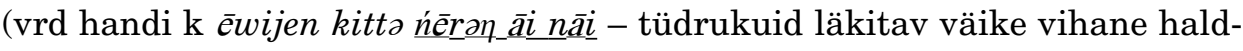

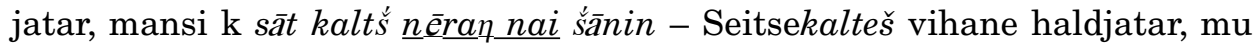
ema). 
Tema rõivastust kirjeldatakse järgmiselt:

Musta looma õnnega kasuka

oma saja õla kallile otsale

mina, haldjatar, panen.

Punase looma õnnega kasuka

mina, haldjatar, panen.

Suure päikesekirja räti

mina, haldjatar, panen

oma sajajuukselisse ilusasse pähe

(Steinitz 1939: 350, värsid 54-63).

\section{B) Maailmavaatav Mees}

Kuukirja püha maja, päikesekirja püha maja

sisemuses,

kuldsete kapjadega kabjalise laua

juures,

kuldsete kapjadega kabjalise laua

peal

kevadoravanaha pühasse raamatusse, sügisoravanaha pühasse raamatusse

seitset kuldset kirja

isand see kirjutab,

kuut kuldset kirja

seal ta kirjutab

(Steinitz 1939: 340-341, värsid 25-37).

Lauad Maailmavaatava Mehe majas on kas kuldkabjalised, kuldjalgsed (W. Steinitzi tekstides) või ühejalgsed (Kannisto \& Liimola 1959: 37).

Teises laulus (tekst nr 31 Kaltaš-imi noorema poja laul) tutvustatakse teda lisaks muule ka nõnda:

Väikeste Poiste Peale Halastav Isand mu nime teatakse,

Väikeste Tüdrukute Peale Halastav Isand mu nime teatakse.

Tüdrukuid läkitava Kaltaši poole, oma ema poole, oma ema poole sooblikarvamehena ${ }^{2}$ pehme palve ma nü̈̈d tõstan, 
karusloomakarva mehena pehme palve ma nüüd tõstan...

(Steinitz 1939: 357, värsid 44-53).

Ta rõivastust kujutatakse järgmiselt:

Põdrapulli kaamusest kaks head saabast mina, isand, panen viie varbaga varbalisse jalga, kuue varbaga varbalisse jalga mina, isand, panen.

Musta looma õnnega kuue, punase looma õnnega kuue oma soobliste kalliste õlgade otsa mina, isand, panen.

Veekalaõnnega vöö, metsloomã̃nnega vöö mina, isand, vööle panen.

Sügisrebasekandiga mütsi, kevadrebasekandiga mütsi sajajuukselisse heledasse pähe seal ma tõstan

(Steinitz 1939: 342-343, värsid 70-85).

Maailmavaatava Mehe peamiseks tundemärgiks on tema kuukirja püha loom, päikesekirja püha loom. Mütoloogilistes tekstides kujutatakse seda sageli tiivulise hobusena.

\section{C) Kazõmi jõe haldjatar}

Üht mu nime nimetatakse:

Musta Kassi Kujuline Väike Haldjatar,

Valge Kassi Kujuline Väike Haldjatar -

mu nime teatakse;

Emasoobli Sisina Väike Haldjatar,

Isasoobli Sisina Väike Haldjatar mu nime teatakse

(Steinitz 1939: 366-367, värsid 69-76).

Talle iseloomulik rõivastuselement on kuukirja püha rätt, päikesekirja püha rätt. Kuid olulisem on see, et tal on patsid nagu metshaldjal ning et ta läheb peopaika jalgsi: 
...metshaldjatüdrukuna patsiline väike haldjatar,

metshaldjatüdruku kolm pikka sammu

mina, haldjatar, võtan,

metshaldjatüdruku neli pikka sammu

mina, haldjatar, võtan

(Steinitz 1939: 366, värsid 64-68).

Kommentaaris kirjutab W. Steinitz: "kāsam nāj ist ein meףk-Mädchen". Just sel põhjusel, et metshaldjaid peeti alama astme jumalusteks, pidid nad liikuma jalgsi (Steinitz 1976: 285). Siin võime ehk näha variatsioone kahe erineva traditsiooni vahel, sest Kazõmi-äärsetele hantidele oli Musta Kassi Kujuline Väike Haldjatar - kāssm imi - väga tähtis tegelane.

\section{D) Allilma Isand}

Väikeseid Tüdrukuid Neelav Isand,

Väikeseid Poisse Neelav Isand -

mu nime teatakse.

Seitsmes Obi-linnas,

kuues Obi-linnas

mu nime teatakse

(Steinitz 1939: 377-378, värsid 4-9).

Kuigi ta valmistub peoleminekuks samuti kui teised vaimud, reisib ta pidumajja hoopis teisel viisil:

Kasetohust külgedega seitsmesse paati,

kasetohust külgedega kuude paati

mina, isand, istun.

Obi-äärsest seitsmest linnast,

Obi-äärsest kuuest linnast

väikesi poisse,

väikesi tüdrukuid neelata võttes

mina, isand, (läbi) lähen

(Steinitz 1939: 381, värsid 80-87).

\section{E) Püha Linna Taat}

Sooloomaküüneline Valitseja, Metsloomakü̈̈neline Valitseja, mina, isand, olen alla lastud.

Oma seitsme harjalatiga unkalise helge, oma kuue harjalatiga unkalise helge 


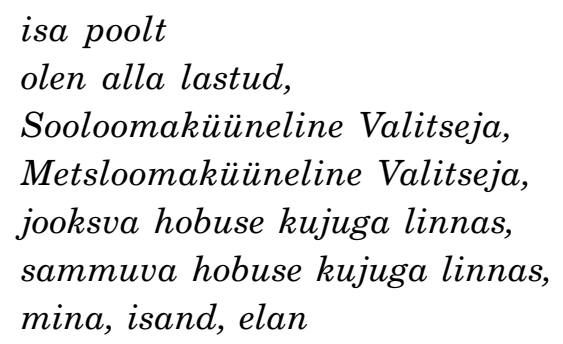

(Steinitz 1939: 384-385, värsid 10-21).

Tuleb rõhutada, et Püha Linna Taat esineb lauludes sageli karu kujul. Sellepärast nimetataksegi teda Sooloomaküüneliseks, Metsloomaküüneliseks Valitsejaks. Éva Schmidti järgi on ta antropomorfseks esinemiskujuks relvis sõjamees, zoomorfseks aga karu (Schmidt 1989: 212-215). Püha Linna Taadi eluase Püha Linn on komikeelsel kujul Vežakarõ (veža - püha, kar - linn) leidnud tee ka maakaartidele. Linn paikneb Lohtotgurtist põhja pool ja seda iseloomustatakse mütoloogilistes tekstides üldiselt kui jooksva hobuse ku-

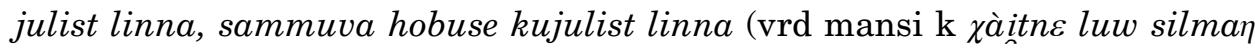

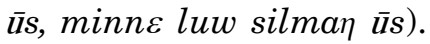

Stereotüüpsete paralleelvärsirühmade esinemine obiugri rahvalauludes on sama tavaline kui meie regilauluski. Sageli leiame samu vormeleid ka juttudest. Võin kinnitada, et paljusid W. Steinitzi publitseeritud lauludes esinevaid stereotüüpseid vormeleid kohtame ka mansi lauludes. Rõhutan, et kuigi kutsumislaulude tekstid suures osas kattuvad, erinevad alati jumaluste elupaikade kirjeldused. Kõik kutsumislaulud on esitaja (K. Maremjanini) koduküla suhtes õigesti orienteeritud - põhja pool elavad jumalused tulevad põhja poolt, lõuna pool elavad lõuna poolt. Jumalused kasutavad neile omaseid liikumisviise. Tekstide kõrvutamine võimaldab meil aimu saada sellest, mis elementidest ja kuidas laulik konkreetse laulu kokku paneb.

Eriti hea ettekujutuse sellest, kuivõrd üksikasjalikke mütoloogia peegeldusi esineb K. Maremjanini esitatud ning W. Steinitzi publitseeritud laulutekstides, annab etenduslaul Surnu elluäratamine (tekst nr 38). Laul algab surnu jutuga sellest, kuidas ränk haigus ta tappis ja kuidas ta pandi puusärki, ning jätkub nii:

Oma väikesi luid kui ma raputan, väikeste loomade poolt need ära kantakse, oma suuri luid kui ma raputan, suurte loomade poolt need ära kantakse.

Pärast seda nü̈̈d sooblisuuruse pehme palve kuhu laotan, 
karusloomasuuruse pehme palve

kuhu laotan?

(Steinitz 1939: 400-401, värsid 13-21).

Järgneb lõik, mis üksüheselt vastab Kevadoravanaha Andamilise Valitseja laulule:

Hommiku ajal kasvanud

kuldse muruga kasvatatud neemel, ôhtu ajal kasvanud

kuldse rohuga kasvatatud neemel;

kevadmetsisekuke sulgedega kaetud küngastel,

sügismetsisekuke sulgedega kaetud küngastel,

seal sa elad,

Kevadoravanaha Andamiline Valitseja,

Sügisoravanaha Andamiline Valitseja,

kuule mind ometi!

(Steinitz 1939: 401, värsid 22-31).

Samal kombel pöördub surnu ka Kaltaš-imi poole:

Tüdrukuid Läkitav Väike Vihane Haldjatar,

Poisse Läkitav Väike Vihane Haldjatar,

kuule mind ometi!

(Steinitz 1939: 402, värsid 55-57).

Järgmisena palub surnu Püha Linna Taati:

Jooksva hobuse kujuline linn, sammuva hobuse kujuline linn, sooblisuuruse pehme palve sinule laotan, karusloomasuuruse pehme palve sinule laotan.

Sooloomakujuline Valitseja, Metsloomakujuline Valitseja, sülesügavusest sinirebaseaugust, põlvesügavusest sinirebaseaugust, kui sa mind välja võtad, ühe köiega seotud seitse musta (looma), ühe köiega seotud kuus musta sulle ohverdan

(Steinitz 1939: 403-404, värsid 77-90). 
Obi-äärsete hantide uskumuste kohaselt käis surija hing enne allilma minekut Kaltaši ja Maailmavaatava Mehe elupaigas. Kui need teda ei peatanud, jõudis hing Püha Linna Taadi juurde, kes viimasena võis teda hoida surnute maale minemast. (Schmidt 1989: 223). Selle teekonna täpse kirjelduse leiamegi tsiteeritud laulust. Ka mansi lauludes tegutseb Püha Linna Taat (jalp ūs ōjka) väikeste poiste ja tüdrukute kaitsjana:

Mu suvenahkadest kasuka rebendeis,

mu sügisnahkadest kasuka rebendeis

istuvad terved tüdrukud,

istuvad terved poisid

(Kannisto \& Liimola 1955: 351).

On veel üks hea näide selle kohta, kui head pärimuse tundjad olid W. Steinitzi tudengitest informandid, - Dimitri Tebitevi 1937. aastal loodud laul Leninist.

Ladimer ju Iljitša,

taiplikuks meheks sündinud olles,

Ladimer ju Iljitša,

meelekaks meheks sündinud olles,

võruna keerlevas rõngasilmas

ringi ta käis,

võruna keerlevas rõngasmaailmas

ringi ta käis,

rikaste meeste paljusid riukaid

mällu ta jättis,

rikka rahva paljusid vempe

meelde ta jättis...

(Steinitz 1939: 454-455, värsid 1-12).

Siis pöördus Lenin vaese rahva poole:

"Viletsates kasukates paljud naised, viletsates jalanõudes paljud mehed rikaste kõhtudega paljudelt meestelt, hõbevatsadega paljudelt naistelt nende liha otsani välja see kurnatakse, nende luu otsani välja see kurnatakse” (Steinitz 1939: 455, värsid 17-22).

Seejärel kutsus ta vaest rahvast ühinema nagu ühe rihmaga kokkuseotud tuhandesuuline hulk. 
Pika käsu hea otsaga

siis ta käskis,

lühikese käsu hea otsaga

siis ta käskis.

Oma kümnehambalise hambulise suuga

nõnda ta rääkis,

oma kahekümnehambalise hambulise suuga

nõnda ta rääkis...

(Steinitz 1939: 456, värsid 31-38).

Sellised värsid, nagu võruna keerlevas rõngasilmas või viletsates kasukates paljud naised, viletsates jalanõudes paljud mehed on obiugri mütoloogilistele lauludele tüüpilised, nagu ka kujundid (millegi) hea ots, kümne/kahekümnehambaline hambuline suu.

Siis ütles Lenin:

"Valvsa auli terava kõrvaga

ma nüüd hästi kuulsin,

valvsa rebase terava kõrvaga

ma nüüd hästi kuulsin.

Rikaste kõhtudega paljudelt naistelt,

hõbevatsadega paljudelt meestelt

meie liha otsani välja see kurnatakse,

meie luu otsani välja see kurnatakse.

Kivisüdame suure vägeva sõjaga

me nüüd üles tõuseme,

Hõbesüdame suure tugeva sõjaga

me nüüd üles tõuseme!”

(Steinitz 1939: 456-457, värsid 41-52).

Nagu näeme, iseloomustatakse Leninit samamoodi nagu karupeole kutsutud üleloomulikku olendit. Laulus kasutatud vormelid valvsa auli terava kõrvaga, valvsa rebase terava kõrvaga on lisaks iseloomulikud ka kangelaslauludele. Muidugi esineb laulude kujundikeeles mitmeid innovatsioone, kuid meie vaatepunktist paistab see siiski üsna traditsioonilise vaimu või kangelase lauluna. Isegi tegutsemise eesmärk - handi rahva aitamine vaesuse ja nälja vastu - on sama.

Nüüd lühidalt ka W. Steinitzi kogumikes publitseeritud juttudest. Neist kuuluvad 21 igapäevast eluolu kirjeldavate narratiivide hulka (jutustajateks K. Maremjanin ja P. Tšamsarov). Ülejäänud lood, mis kogumikes on liigitatud muinasjuttudeks, kuuluvad tegelikult mütoloogiliste muistendite hulka. Seda 
tunnistab ka W. Steinitz ise jutule (śempor-kivi) lisatud kommentaaris, kirjutades:

Selles ning kahes järgnevas lõigus muutuvad muinasjutu peategelased - poeg, vanem vend ja ema - vaimudeks, kes seavad ennast sisse oma pühapaikades. Selline lõpp on kangelasmuinasjuttudele ning kangelaslaulule tü̈̈piline, tegelikult on need lood rituaalselt austatud esivanema või muu vaimu elust (Steinitz 1976: 245).

Nende lugude kangelane esineb sageli kui Naise Vennapoeg, väike moś-mees, moś-naine või por-naine. Samamoodi tutvustatakse tegelasi obiugri muistendites üldse. Need algavad sageli vormeliga "elasid õde-venda", "elas mośnaine koos vennaga" või "elas naise poeg koos oma tädiga (vanaemaga)". Vaid üksikutest vihjetest saab kuulaja aru, et tegemist pole lihtsurelikega. Mõnikord jäävad nad jutu lõpuni identifitseerimata, mõnikord pannakse nad muistendi lõpuosas paika müütilistest lauludest pärinevate vormelitega, harva öeldakse nende nimed otse välja. Võib üsna kindlalt väita, et mütoloogilise sisuga juttudes tähendab õde või moś-naine kas mõnda jumalust või müütilist esivanemat. Sama kehtib ka venna kohta. Sel juhul toimub jutu tegevus müütilisel loomisajastul ning mõjutab mingil viisil tulevast maailmakorda. Näiteks esineb eelmisel sajandil üles kirjutatud mansi loomismuistendi kangelane nime all tāri $\gamma$-péśsimal'a-sov - Kure Puusalt Võetud Nahk. Ta külastab Vetevürsti, Kuuvanameest, Päikesenaist ja teisi üleloomulikke olendeid, võitleb mõnega neist, mõne aga kavaldab üle, saades endale naisteks võidetud vastaste naised ja tütred. Lõpuks jõuab ta koos kuue naisega õnnelikult tagasi vanemate juurde. Need võtavad poja pidusöögiga vastu. Peo ajal ütleb ema: "Saagu inimene nüüdsest olema endises maailmas, saagu inimene olema praeguses maailmas, saagu kõikjal olema naiste paigad ja meeste paigad, mida asustagu palju vaestes kasukates naisi ja palju vaestes kasukates mehi. Ning hakaku nad sulle ohvriks tooma põdrapulle ja põdralehmi!" Järgmisel hommikul ütleb ema: "Sa, pojake, jääd nüüd siia, alumisse taevasse, meie aga läheme ülemisse taevasse. Alumises taevas saab sinust mees, kes kaitseb maailma - Mir-susne-hum -, sinu isa saab ülemises taevas kõrgeimaks jumalaks - Numi-Toorumiks -, minust aga saab Kalteš" (Šestalova-Fidorovitš 1992: 22-23).

Ühes W. Steinitzi kogutud jutus (śempər-kivi, millest on ära toodud kaks varianti) ilmub venna äraoleku ajal kotta Seitsme Soobli Kõrgune Vägilane, kes palub õel oma peast täisid otsida. Venna kojutuleku ajaks ta lahkub. Viimaks saab õde ta naiseks. Ta sünnitab poja, kes kasvab nii kiiresti, et Seitsme Soobli Kõrgune Vägilane hakkab kahtlema, kas ta ikka on poisi isa. Poisil seisab ees rida katsumusi, näiteks peab ta võistlema oma seitsme 
vennaga kivi lingutamises. Nagu Maailmavaatav Mees (Naise Poeg, Naise Vennapoeg) kunagi, võidab poiss oma vennad. Seejärel saadab isa ta koos poegadega Seitsme Kivisilmse Vägimehe linna. Seal põgeneb poiss kinnivõtjate küüsist ning ujub kaurina tagasi koju. Lugu lõpeb suure pidusöögiga, mille ajal onu ütleb poisile: "Sa mine nüüd oma maale! Hommikul saamata jäänud ohvrid võta vastu õhtul, õhtul saamata jäänud ohvrid võta vastu hommikul!" Siis ütleb ta oma õele: "Sa mine oma iseenesest veest kerkinud kauri pesaga mättale, oma iseenesest veest kerkinud jääkauri pesaga mättale. ${ }^{3}$ Hommikul saamata jäänud ohvrid võta vastu õhtul, õhtul saamata jäänud ohvrid võta vastu hommikul!" Onu ütleb: "Ise lähen oma jooksva hobuse kujulisse linna, oma sammuva hobuse kujulisse linna. Väikeste tüdrukute hingi peatades olen seal, väikeste poiste hingi peatades elan seal" (Steinitz 1976: 244-263).

Nagu eespool näiteks toodud mansi muinasjutukatkendis, nii jagavad jumalused-haldjad loomisajastu lõppedes ka siin omavahel elupaigad ja funktsioonid. On selge, et jooksva või sammuva hobuse kujulises linnas elav onu on Püha Linna Taat, kellest uskumuste kohaselt sõltus suuresti inimelu kestus maa peal. Loomislugude linnu pesa kõrvale saadetud naine on Kaltaš. Sellest tunnistab selgesti teises handi jutus (Naise Vennapoeg ja südameta tsaar) esinev vormel:

Toitu andvale Obile, kala andvale Obile, nelja Obi-neeme hargnemiskohta mine! Hanekisaga täidetud looklevatele jõeharudele, pardikisaga täidetud looklevatele jõeharudele mine! Oma iseenesest veest kerkinud kauri pesaga mättale, oma iseenesest veest kerkinud jääkauri pesaga mättale mine! [---] Väikeste tüdrukute, väikeste poiste eluiga kindlaks määrates ela seal. Kauaks elama määratud väikestele poistele määra pikk iga, kauaks elama määratud väikestele tüdrukutele määra pikk iga! (Steinitz 1939: 301-302).

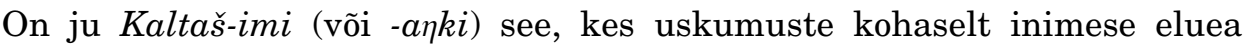
määrab. Lugude peategelane aga on Maailmavaatav Mees. Talle ütleb onu:

Sa, nõbu, mine toitu andva Obi, kala andva Obi ülemjooksule, oma kuldse muruga, kuldse rohuga kaetud neemele, oma kevadiste metsisekukkede sulgedega ülepuistatud eelmägedesse, sügiseste metsisekukkede sulgedega ülepuistatud eelmägedesse, oma vibunööri otsas rippuvasse linna, oma kinganööri otsas rippuvasse linna, oma kuukirjusse pühasse majja, oma päikesekirjusse pühasse majja! Oma kuldkabjalise laua taga istu oma kevadistest oravanahkadest, sügisestest oravanahkadest püha raamatut lugedes! - Oma kuukirju 
püha hobuse seljas ratsuta ümber võruna keerleva rõngasmaailma, ratsuta ümber võruna keerleva haldjate ilma! (Steinitz 1939: 300301).

Lugu meenutab paapuate muistendeid müütilisel loomisajal tegutsevatest dema-jumalustest, kes omavahel suheldes ja üksteist tappes panevad aluse eri suguharudele, kultuurtaimedele, koduloomadele ja hilisemale maailmakorrale.

Lõpuks võime kõige eelneva valgusel kinnitada kõigepealt seda, et K. Maremjanin, P. Põrõsev ja teised noored W. Steinitzi informandid olid oma kodupaiga folkloori väga head tundjad, kes mitte ainult ei mäletanud traditsioonilist repertuaari, vaid suutsid selle põhjal luua ka uusi tekste. Võime ka kindla veendumusega öelda, et ilma nende tekstideta, mis avaldati handialaste tööde kahes köites, haigutaks obiugrilaste folkloori- ja mütoloogiaalastes uurimustes märkimisväärne auk.

\section{Kommentaarid}

${ }^{1}$ Siin peetakse silmas Maailmavaatavat Meest.

${ }^{2}$ Sooblinahana pehme.

${ }^{3}$ Vihje maailmaloomise loole. Väljend iseenesest veest kerkinud peab tähendama, et mätas kauri pesaga oli olemas juba enne aegade algust, vastandina maale, mille kaur ürgmere põhjast pinnale tõi.

\section{Kirjandus}

Great Bear $=$ Honko, Lauri \& Timonen, Senni \& Branch, Michael 1993. The Great Bear: A Thematic Anthology of Oral Poetry in the Finno-Ugrian languages. Suomalaisen Kirjallisuuden Seuran Toimituksia 533. Pieksamäki: Finnish Literature Society

Kannisto, Juha Artturi \& Liimola, Matti 1955. Wogulische Volksdichtung I: Texte mytischen Inhalts. Suomalais-Ugrilaisen Seuran Toimituksia 101. Helsinki. SuomalaisUgrilainen Seura.

Kannisto, Juha Artturi \& Liimola, Matti 1959. Wogulische Volksdichtung V: Aufführungen beim Bärenfest. Suomalais-Ugrilaisen Seuran Toimituksia 116. Helsinki. Suomalais-Ugrilainen Seura.

Lintrop, Aado 1997. Khanty Bear-Feast Songs. Collected by Wolfgang Steinitz. Folklore: An Electronic Journal of Folklore, 6, lk 70-98 (http://www.folklore.ee/folklore/vol6/ steinitz.htm - 11. november 2006). 
Schmidt, Éva 1989. Bear Cult and Mythology of the Northern Ob-Ugrians. Hoppál, Mihály (toim). Uralic Mythology and Folklore. Ethnologica uralica 1. Budapest: Ethnographic Inst. of the Hungarian Acad. of Sciences, lk 187-232.

Steinitz, Wolfgang 1939. Ostjakische Volksdichtung und Erzählungen aus Zwei Dialekten 1. Õpetatud Eesti Seltsi Toimetused XXXI. Tartu: Õpetatud Eesti Selts = Steinitz, Wolfgang 1975. Ostjakologische Arbeiten I: Ostjakische Volksdichtung und Erzählungen aus zwei Dialekten: Texte: Für die Neuherausgabe wissenschaftlich bearbeitet von Gert Sauer. Den Haag: Mouton \& Budapest: Akadémiai Kiadó.

Steinitz, Wolfgang 1976. Ostjakologische Arbeiten II: Ostjakische Volksdichtung und Erzählungen aus zwei Dialekten: Kommentare: Für Herausgabe wissenschaftlich bearbeitet von Gert Sauer und Brigitte Schulze. Budapest: Akadémiai Kiadó.

Šestalova-Fidorovitš 1992 = Шесталова-Фидорович, О. (tõlk). Сбященныци сказ о сотворении зелли: Мансийские мифы. Ленинград \& Ханты-Мансийск: Стерх белый журавль = Ромбандеева, Евдокия И. 1993. История народа манси (вогулов) и его духовная культура. Сургут: Северный дом, lk 136-167.

Tšernetsov 1974 = Tschernjetzow, Valeri N. Bärenfest bei den Ob-Ugriern. Acta Ethnographica Academiae Scientiarum Hungaricae 23: 2-4, Budapest: Akadémiai Kiadó, lk 285-319.

\title{
Summary
}

\section{The Young Performers of an Old Tradition}

\author{
Aado Lintrop
}

Key words: Khanty folklore, Khanty mythology, Ob-Ugric folklore, Ob-Ugric mythology, mythological songs of the Khanty, Khanty legends, bear wake, bear feast, bear feast songs

In my article, I shall deal with the Khanty narratives and song texts published in two volumes (the first and the third) of Ostjakologische Arbeiten. There are also 516 riddles published in the third volume but these will not be covered in the current paper. The 106 longer texts represent 9 different Khanty dialects, 68 of them are narratives, and in general outline their origins are the following: 49 texts were received from Kirill Maremianin, 18 texts from Prokop Pyrysev, 6 texts from P. Chamzarov, 5 texts from A. Olgina, 3 texts from Dimitri Tebitev, and 3 texts from G. Artanzeev. 20 texts were collected from different persons by Steinitz during his expedition in 1935, and one song text originates in Leningrad in 1963. Of the texts, 29 were written down personally by the informants and controlled or corrected by W. Steinitz, all other texts were put down by Steinitz. One story and 18 songs performed by Maremianin were recorded on phonograph records in 1936.

Most of the texts have a remarkable mythological background. I personally find it interesting that 85 texts were collected from the students of the University of Northern Peoples in Leningrad. In Estonia, we are accustomed to elderly people being the main 
informants of folklorists or linguists. In 1936, the oldest student of Steinitz - Dimitri Tebitev - was about 30, Kirill Maremianin was 29, and Prokop Pyrysev only 18 years old. Nevertheless, some of them seemed to know a very specific song and story repertoire. How good experts of folklore and mythology were these young men? What is the position of their stories and songs on the folkloric landscape of Ob-Ugrians? I will try to seek answers to these two questions.

It follows from the bear feast song texts that the festival house is situated to the north of the abode of the World Surveyor Man, but to the south of the Kazym River mistress. If we happen to deal here with the repertoire of a specific bear feast, it must have taken place somewhere between the settlement of Belogorie and the estuary of Kazym. If we have a look at the map published in the second volume, we will find that Lokhtotgurt, the native village of the singer, is situated precisely in that region.

Stereotypical parallel groups of verses are a common feature of Ob-Ugric folk songs. Often the same formulae are also present in stories. I may confirm that several stereotype formulae in the songs published by Steinitz may be found also in Mansi songs. To sum up, I would like to draw attention to the fact that while the texts of calling songs largely coincide, the descriptions of the abodes of deities are always different. All the calling songs are accurately oriented in relation to the performer's native village - deities residing in the north come from the north, those residing in the south come from there. The deities display characteristic ways of moving about.

There is yet another good example of how good experts of tradition the student informants of Steinitz were - the song Lenin created by D. Tebitev in 1937. As we can see, Lenin is characterized as a supernatural being summoned to a bear feast. The verses with the sharp ear of the alert long-tailed duck, with the sharp ear of the alert fox used in the song are also typical of heroic songs. Of course, there are some innovations in the figurative style of the song, but from our perspective it looks like a quite traditional spirit's or hero's song. Even the purpose of the protagonist is similar - to safeguard the Khanty people against misery.

Of the narratives, 21 texts are stories about everyday life told by K. Maremianin and P. Chamzarov. Most of the texts, although classified by Steinitz as fairy tales (Märchen), are mythological stories. To the ending of a text called "The śempər-stone" Steinitz himself added the following comment: "In this and the following two paragraphs the main heroes of the fairy tale - the son, his mother and his older brother transform into spirits, establishing themselves in their holy places. This is the usual conclusion of the hero fairy tales (or stories) and hero songs, which are actually reports about the life of the ritually admired progenitor or other spirit." (Steinitz 1976: 245).

It may be confirmed that K. Maremianin, P. Pyrysev, and the other young informants of W. Steinitz were good experts indeed in their homeland's folklore. Without the collection of Khanty texts published by Steinitz in the two volumes of Ostjakologische Arbeiten, there would have been a remarkable gap in the studies of Ob-Ugrian folklore and mythology. 